\title{
Spatial mapping of leaf area index using hyperspectral remote sensing for hydrological applications with a particular focus on canopy interception
}

\author{
H. H. Bulcock and G. P. W. Jewitt \\ School of Bioresources Engineering and Environmental Hydrology, University of KwaZulu-Natal, Pietermaritzburg, \\ South Africa
}

Received: 2 June 2009 - Published in Hydrol. Earth Syst. Sci. Discuss.: 14 September 2009

Revised: 18 February 2010 - Accepted: 19 February 2010 - Published: 25 February 2010

\begin{abstract}
The establishment of commercial forestry plantations in natural grassland vegetation, results in increased transpiration and interception which in turn, results in a streamflow reduction. Methods to quantify this impact typically require LAI as an input into the various equations and process models that are applied. The use of remote sensing technology as a tool to estimate leaf area index (LAI) for use in estimating canopy interception is described in this paper. Remote sensing provides a potential solution to effectively monitor the spatial and temporal variability of LAI. This is illustrated using Hyperion hyperspectral imagery and three vegetation indices, namely the normalized difference vegetation index (NDVI), soil adjusted vegetation index (SAVI) and Vogelmann index 1 to estimate LAI in a catchment afforested with Eucalyptus, Pinus and Acacia genera in the KwaZulu-Natal midlands of South Africa. Of the three vegetation indices used in this study, it was found that the Vogelmann index 1 was the most robust index with an $R^{2}$ and root mean square error (RMSE) values of 0.7 and 0.3 respectively. However, both NDVI and SAVI could be used to estimate the LAI of 12 year old Pinus patula accurately. If the interception component is to be quantified independently, estimates of maximum storage capacity and canopy interception are required. Thus, the spatial distribution of LAI in the catchment is used to estimate maximum canopy storage capacity in the study area.
\end{abstract}

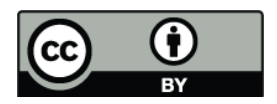

Correspondence to: H. H. Bulcock (204501831@ukzn.ac.za)

\section{Introduction}

To the water resources planner who is ultimately interested in the amount of water available, the vegetation canopy is a barrier for precipitation to cross before reaching the soil and possibly making its way to the river or dam (Davies, 2003). In South Africa, it has been estimated that commercial forestry uses about $5 \%$ of the total available water supply (GCIS, 2007). By virtue of their physiology, extent of coverage and location in the high rainfall catchment areas of South Africa, commercially grown tree species impact on the hydrological resources of the country with an even more significant impacts at smaller spatial and temporal scales. Between 1986 and 1998, the area under forestry in South Africa increased by $27 \%$ to $1.44 \times 10^{6}$ ha, which constitutes $1.18 \%$ of the arable land (Gush, 2000), but is reported to have decreased to approximately $1.27 \times 10^{6}$ ha over the past five years, because of fire and withdrawal of some land from production (Godsmark, 2008).

Vegetation cover or land cover influences hydrological processes in many ways. Interception and transpiration is a loss or sink term in the water balance of a catchment, and evaporation and transpiration losses have been shown to influence downwind rainfall at regional scales (Shultz and Engman, 2000). Forest stand description typically includes factors related to the eco-physiological processes responsible for forest growth. One of those factors is the stand leaf area index (LAI). LAI is related to processes such as canopy interception, transpiration, photosynthesis, and leaf litterfall, and used as an input to various ecosystem and hydrological models (Sprintsin et al., 2007) such as the ACRU Agrohydrological model (Schulze, 1995), the 3PG model (Landsberg and

Published by Copernicus Publications on behalf of the European Geosciences Union. 
Waring, 1997) and SIMPLE model (Hörmann, 2007). Nemani et al. (1993) found that LAI varies with microclimate and soil water conditions. In their study, hilltops showed a lower LAI owing to less available water and therefore more stress, while the bottom of hill slopes had more water, less stress, higher temperatures, possibly more nutrients, and therefore higher LAI values.

Accurate monitoring and assessment of water resources is necessary for sustained water resource management. Earth observation data have formed the basis for acquiring data remotely for many years (Landgrebe, 1999) and are now viewed as a time and cost-effective way to undertake largescale monitoring (Okin et al., 2001). Remote sensing has been widely recognised as a valuable tool for the detection and analyses of data, both spatially and temporally, with significant advantages over point sources (Bongonko, 2005) and is becoming increasingly useful in southern Africa, where components of the hydrological cycle, such as rainfall, evaporation, plant water use and runoff show great variation in both time and space (Jewitt, 2002), and where traditional monitoring is extremely limited. The past decade has seen a particularly rapid increase in the number of launched satellites, as well as an improvement in both spatial and spectral resolution of data they produce. The planned launch of several new satellites will lead to further improvements in the quality of remotely sensed data (Dye et al., 2002). The ability to rapidly assess LAI using vegetation indices (VIs) from remotely sensed imagery provides a means to rapidly assess stand productivity over a wide geographic area. There are a growing number of studies that are using hyperspectral remote sensing to estimate the LAI of forest and crop canopies such as those by Delegido et al. (2008), Haboudane et al. (2004) and Zhang et al. (2005). In addition to providing alternative means to estimate forest productivity in the long term, this approach may complement existing approaches aimed at estimating water use of various crops in fulfilment of the National Water Act of 1998. The Act makes provision for the classification of various crops and land use practices as streamflow reduction activities (SFRA), which are then subject to controls to ensure equity in water allocation (Ghebremicael et al., 2004). Current tools to assess water use by commercial afforestation tend to focus on total evaporation and are limited in their consideration of interception from forest canopies as a separate process.

In this study, data from the Hyperion sensor on board the EO-1 satellite, the first hyperspectral sensor to operate from space was used to estimate LAI in a small afforested catchment in the KwaZulu-Natal Midlands of South Africa. The satellite estimates were verified using measurements obtained from the field site using a handheld LI-COR LAI-2000 plant canopy analyzer. The information from this analysis was then used to map interception storage capacity over the same area. Ultimately, this approach will provide for better spatial estimation of canopy interception, which is a little studied aspect of forest water use in South Africa.

\section{Canopy interception and leaf area index}

Interception is one of the most neglected and underestimated processes in rainfall-runoff analysis. Some models disregard it completely, based on the assumption that it is generally a small portion of the total evaporation (Savenije, 2004). However, Beven (2001) states that evaporation from intercepted water on leaf surfaces in rough canopies can be very efficient and could form a significant component of the total water balance in some environments. In a forest with a closed canopy, the interception of precipitation is a major component of the influence that forests exert on the hydrological cycle (Jewitt, 2005) and may be simply defined as the difference between gross rainfall and net rainfall (net rainfall being the sum of stemflow and throughfall). A broader definition by Savenije (2004) is that interception accounts for the part of the rainfall that is captured before it can take part in the subsequent runoff and sub-surface processes. This definition is more useful for hydrological modelling, where the focus is surface runoff, the soil moisture budget, transpiration, recharge and ground water processes.

Interception loss from forests depends on the atmospheric conditions that drive evaporation and rainfall characteristics, but also the nature and density of the forest stand. This depends on the tree physiology, but also management practice and the age of the trees, older trees have denser canopies and correspondingly higher canopy storage, and higher interception loss than younger trees (Jewitt, 2005). The dependence of the storage capacity on the LAI is highlighted by considering Eq. (1) developed by von Hoyningen-Huene (1981) which is still recognised as an accurate, non-crop specific estimate of maximum storage capacity $\left(S_{\max }^{c}\right)(\mathrm{mm})$ as highlighted by Kozak et al. (2007).

$S_{\max }^{c}=0.935+0.498(\mathrm{LAI})-0.00575\left(\mathrm{LAI}^{2}\right)$

The subsequent process of throughfall is the water that falls to the ground either directly through gaps in the canopy, or indirectly by having dripped off leaves, stems and branches after the storage capacity has been reached. The amount of direct throughfall and, conversely indirect throughfall is controlled by the canopy coverage (c), a measure of which is the LAI (Davies, 2003).

Van Dijk and Bruijnzeel (2001a, b) modified the wellknown Gash et al. (1995) revised model allowing it to be applied to rapidly growing vegetation where the LAI is changing through time. For this model, LAI is defined as the cumulative one-sided area of (healthy) leaves per unit area. LAI and $c$, can be related to one another via the Beer-Lambert equation which describes the attenuation of radiation (i.e. photosynthetically active radiation, PAR) as a function of LAI. PAR however, does not penetrate far through leaves, therefore the Beer-Lambert equation may be expressed in terms of canopy cover fraction using similar 


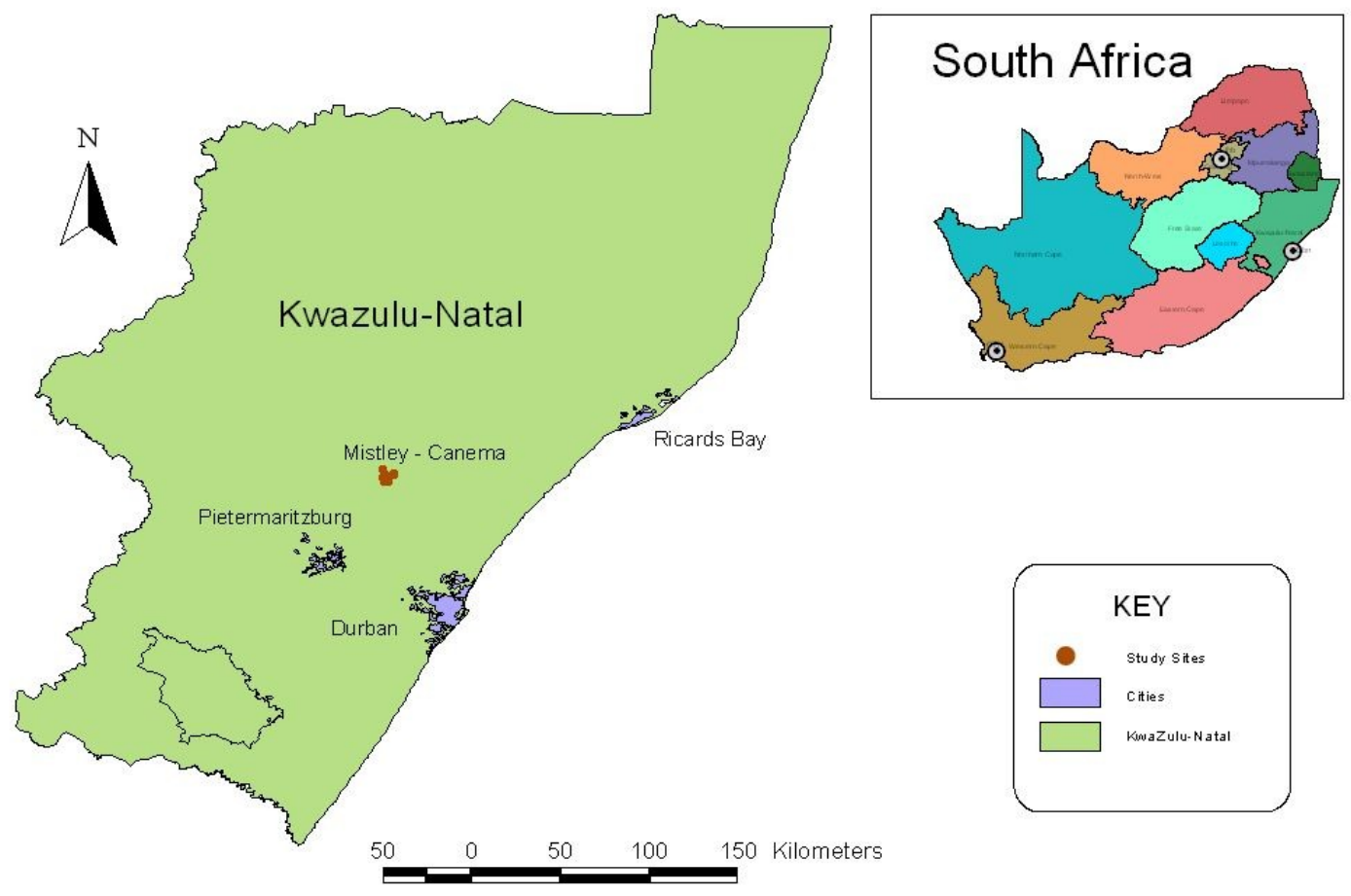

Fig. 1. Location of Mistley-Canema Estate in KwaZulu-Natal, South Africa.

parameters. The relationship between $c$ and LAI is thus given by Eq. (2).

$c=1-e^{-K . \mathrm{LAI}}$

where $K$ is the extinction coefficient. The value of $K$ for a particular radiation wavelength depends on the inclination angle and distribution of the leaves, and for PAR usually ranges between 0.6 and 0.8 in forests (van Dijk and Bruijnzeel, 2001a, b).

The water that is retained on the leaves is then evaporated from the wet canopy surface, which has been found to evaporate at rates in excess of available net radiation and potential evaporation because of advection and the low aerodynamic resistance of wet canopies (Schulze, 1995; Davids et al., 2005). Equation (3) provides a conservative estimate of enhanced wet canopy evaporation rate, $E_{w}\left(\mathrm{~mm} \mathrm{day}^{-1}\right)$ (Schulze, 1995), which incorporates LAI as a governing parameter.

$E_{w}=E_{r}(0.267 \mathrm{LAI}+0.33)$ for $\quad \mathrm{LAI}>2.7$

where: $E_{r}-\mathrm{A}$-pan equivalent reference potential evaporation $\left(\mathrm{mm} \mathrm{day}^{-1}\right), \mathrm{LAI}$ - Leaf area index (dimensionless)

By implication, wet canopy evaporation proceeds at a rate of 1.67 times that of potential evaporation for LAI=5.

Considering canopy interception is dependant on the storage capacity $\left(S_{c}\right)$, canopy cover $(c)$ and wet canopy evaporation $\left(E_{w}\right)$, all of which are related to the LAI. Von Hoyningen-Huene (1983) in Schulze (1995) developed
Eq. (4) based on extensive research conducted on a number of agricultural crops and related their interception loss $\left(\mathrm{mm} \mathrm{day}^{-1}\right)$ to gross daily rainfall $\left(P_{g}\right)$ and LAI as:

$$
\begin{aligned}
I_{l} & =0.30+0.27 P_{g}+0.13 \mathrm{LAI}-0.013 P_{g}^{2} \\
& +0.0285 P_{g} . \mathrm{LAI}-0.007 \mathrm{LAI}^{2} .
\end{aligned}
$$

The LAI and gross precipitation are used as the canopy structure and climatic descriptors respectively. Although the equation was developed for agricultural crops, Schulze (1995) found that the equation performed well on Pinus patula, and therefore it was deduced that the Von Hoyningen-Huene approach has potentially widespread application and is encouraged as the interception loss estimator in the ACRU agrohydrological model (Schulze, 1995).

\section{Methodology}

\subsection{Site description}

The Mistley-Canema estate is situated in the Seven Oaks district in the KwaZulu-Natal Midlands, South Africa as shown in Fig. 1. According to Camp (1997) the South African Bioresource Group (BRG) is "moist midlands mistbelt". The climate is humid, with an annual rainfall ranging from $800 \mathrm{~mm}$ to $1280 \mathrm{~mm}$ per annum and the mean annual temperature is $17^{\circ} \mathrm{C}$. The natural vegetation of the area was previously indigenous Themeda triandra grassland. Only a few relic patches of Themeda triandra grassland remain, as 
the high potential of the arable areas has meant that little value has been placed on the natural vegetation. Commercial afforestation has long been practiced in the area and is the most widespread land use, with gum (Eucalyptus), pine ( $P i$ nus) and wattle (Acacia) being the species of choice. Sugarcane is also grown at sites where drainage of cold air is good, ensuring that no frost or only light frost occurs (Everson et al., 2006).

\subsection{Hyperion hyperspectral satellite}

Hyperspectral images acquire many, very narrow, contiguous spectral bands, covering the visible, near-infrared, midinfrared, and thermal infrared regions of the electromagnetic spectrum, allowing for the construction of an almost continuous spectrum for every pixel in the scene. The Hyperion sensor on board the EO-1 satellite was the first hyperspectral sensor to operate from space and orbits at an altitude of $705 \mathrm{~km}$. This sensor has a spectral resolution of $10 \mathrm{~nm}$ and covers 242 bands from $380-2500 \mathrm{~nm}$. The spatial resolution of the image is $30 \mathrm{~m}$ and the swath width of an image is $7.5 \mathrm{~km}$. The Hyperion data used in this study were acquired on 21 July 2006 (Govender et al., 2007).

\subsection{LAI measurement and model development}

The LI-COR LAI-2000 plant canopy analyzer (LAI-2000, LI-COR, Inc., Lincoln, Nebraska, USA) was used to measure plantation forest LAI in each of the three tree species. Due to the height of the trees, it was not possible to take measurements above the canopy. Thus the "remote mode" method was used, i.e. two control units are used to log the above and below canopy readings respectively. At each of the four study sites (i.e. 12 year old pine, 15 year old pine, 4 year old wattle and 10 year old eucalyptus) ten sets of four reading were taken at each plot for model development and then repeated for model validation. Each of the points were taken at random beneath the canopy. A separate syncronised instrument was located in an open area and was taking readings every $15 \mathrm{~s}$, representing the above canopy readings. During the data processing stage the above and below canopy readings were compared to determine the fraction of light transmitted or absorbed by the canopy. A sunlit canopy was avoided by taking readings just before sunset when the solar elevation is low (below $45^{\circ}$ ). A $45^{\circ}$ view lens was used to restrict the view of the sensor. The models were developed by overlaying the points where the LAI readings were taken on the images that had been corrected with each of the three vegetation indices (i.e. NDVI, SAVI and Vogelmann 1). The pixel values for each point were then extracted and related to its corresponding LAI value. A linear regression model was then fitted to the data using Microsoft ${ }^{\circledR}$ Excel 2003.

\subsection{Atmospheric correction of Hyperion image}

Atmospheric correction is a pre-processing procedure that is undertaken to compensate for the effects of atmospheric particles through absorption and scattering of the radiation. The objective of performing an atmospheric correction is to retrieve the surface reflectance from the remotely sensed image by removing atmospheric effects. The conversion involved the removal of atmospheric absorptions and scattering as well as removal of the shape of the solar irradiance spectrum. Atmospheric and radiometric corrections were performed using the ENVI 4.3 remote sensing software package using the empirical line method of atmospheric correction. This method compares radiance values reflected from the surface to reflectance values measured on the ground with a calibrated hand-held spectrometer (Research Systems Inc., 2005). Using several ground truth data targets, the relationship between radiance at sensor and reflectance on the ground can be extracted. Since the effect of the atmosphere is multiplicative (by gasses) and additive (by aerosols) linearity is assumed in each wavelength (i.e. image layer) and a gain and offset are used as estimates of these atmospheric effects on radiance. After calculating these for all wavelengths, the gains and offsets could be applied to the image as a whole and the reflectance in all pixels can be estimated.

\subsection{Vegetation indices}

The relation between remotely sensed measurements and vegetation parameters is captured by various vegetation indices. A vegetation index is defined as a mathematical combination of channels or bands that indicates the presence or condition of green vegetation (Lillesand and Kiefer, 1999). Much work has centered on seeking correlations between various plant canopy attributes and a variety of vegetation indices (Dye et al., 2002). The most commonly used vegetation indices utilize the information contained in the red and near infrared reflectances; either as ratios or differences (Dye et al., 2002). Live green plants absorb solar radiation in the photosynthetically active radiation (PAR) spectral region (between 400 and $700 \mathrm{~nm}$ ), which they use as a source of energy in the process of photosynthesis. Leaf cells have also evolved to scatter (i.e. reflect and scatter) solar radiation in the near-infrared (NIR) region (700 to $1300 \mathrm{~nm}$ ) because the energy is not sufficient to synthesize organic molecules. If the plant absorbed strongly in the NIR, the result would be that the plant would overheat (Gates, 1980). Vegetation indices are routinely used to determine green biomass, green leaf area, LAI, stand biomass, percent ground cover, amount of photosynthetically active vegetation, photosynthesis activity and productivity (Baret and Guyot, 1991). Hundreds of vegetation spectral indices have been reported in the literature, but few are commonly used and have been tested in different vegetation studies. Near infrared/Red (NIR/R) spectral band ratios such as the Soil Adjusted Vegetation Index 
(SAVI), Eq. (5) and Normalized Difference Vegetation Index (NDVI), Eq. (8) are widely used to estimate LAI over large areas.

The SAVI is expressed as follows:

$\mathrm{SAVI}=\frac{(1+L)(\mathrm{NIR}-\mathrm{R})}{\mathrm{NIR}+\mathrm{R}+\mathrm{L}}$

where $L=0.5$, and is an adjustment factor to minimize the backscatter effect of soil background reflectance through the canopy.

According to Schultz and Engman (2000), LAI is related to SAVI as follows:

$\mathrm{SAVI}=c_{1}-c_{2} e^{-c 3 . \mathrm{LAI}}$

where:

$c_{1}=0.69 ; \quad c_{2}=0.59 ; \quad c_{3}=0.91$

Therefore : $\quad \mathrm{LAI}=\frac{-\ln (\mathrm{SAVI}+0.371)}{0.48}$

The Normalized Difference Vegetation Index (NDVI) is one of the oldest, most well known, and most frequently used VIs having been used to study vegetation and phenology since the early 1970's. The combination of its normalized difference formulation and use of the highest absorption and reflectance regions of chlorophyll make it robust over a wide range of conditions and because it minimises the effects of topography, no prior knowledge of the ground conditions are required, and it is sensitive to the photosynthetically active vegetation (McGwire et al., 2000). It can, however "saturate" in dense vegetation conditions when LAI becomes high. Saturation occurs when the vegetation index value no longer increases with an increase in biomass or LAI (Dye et al., 2002). The NDVI ratio is the ratio of shortwave infrared and red reflectance. NDVI is defined by the following equation:

$\mathrm{NDVI}=\frac{\mathrm{NIR}-\mathrm{red}}{\mathrm{NIR}+\mathrm{red}}$

Another vegetation index is the Vogelmann Red Edge Index 1 (VOG1) (Vogelmann, 1993), which is a narrowband reflectance measurement that is sensitive to the combined effects of foliage chlorophyll concentration, canopy leaf area, and water content. Applications include vegetation phenology (growth) studies, precision agriculture, and vegetation productivity modelling. VOG1 is defined by the following equation:

VOG1 $=\frac{\text { Reflectance at } 740 \mathrm{~nm}}{\text { Reflectance at } 720 \mathrm{~nm}}$

Narrowband greenness VIs are a combination of reflectance measurements sensitive to the combined effects of foliage chlorophyll concentration, canopy leaf area, foliage clumping, and canopy architecture. Narrowband greenness VIs are designed to provide a measure of the overall amount and quality of photosynthetic material in vegetation, which is essential for understanding the state of vegetation. These VIs use reflectance measurements in the red and near-infrared regions to sample the "red edge" portion of the reflectance curve. The "red edge" is a term used to describe the steeply sloped region of the vegetation reflectance curve between $690 \mathrm{~nm}$ and $740 \mathrm{~nm}$ that is caused by the transition from chlorophyll absorption and near-infrared leaf scattering. Use of near-infrared measurements, with much greater penetration depth through the canopy than red measurements, allows estimation of the total amount of green material in the column (RSI, 2005).

Narrowband greenness VIs are more sophisticated measures of general quantity and vigor of green vegetation than the broadband greenness VIs. Making narrowband measurements in the red edge allows these indices to be more sensitive to smaller changes in vegetation health than the broadband greenness VIs, particularly in conditions of dense vegetation where the broadband measures can saturate. Narrowband greenness VIs are intended for use with high spectral resolution imaging data, such as that acquired by hyperspectral sensors (RSI, 2005).

\subsubsection{Accuracy assessment}

To evaluate how well the estimated values obtained from the remotely sensed data compare to the observed data measured using the LI-COR LAI canopy analyser, the Root Mean Squared Error (RMSE) (Eq. 10) statistic was used. The closer the RMSE is to zero, the better the result.

$\mathrm{RMSE}=\sqrt{\frac{\sum^{n}(E-O)^{2}}{n}}$

Where: $E$ - The estimated value, $O$ - the observed value, and $n-$ the number of samples.

\section{Results}

The LAI values were measured on the 21 June 2007 using the LI-COR LAI- 2000 canopy analyzer as described in Sect. 3.3. These were used to develop the relationships with the three vegetation indices and are shown in Table 1.

The relationships established between the measured LAI of all the sampled species and the three vegetation indices used are shown in Figs. 2-4.

From Fig. 2 it can be seen that the Pine $12 \mathrm{yr}$ and the Wattle $4 \mathrm{yr}$ can be estimated well when using the NDVI. The LAI of Pine 15 will be underestimated and Eucalyptus $10 \mathrm{yr}$ will be overestimated using the regression model obtained.

From Fig. 3 it can be observed that Pine 12 can be fairly well estimated, but the other species are scattered both above and below the regression model. 


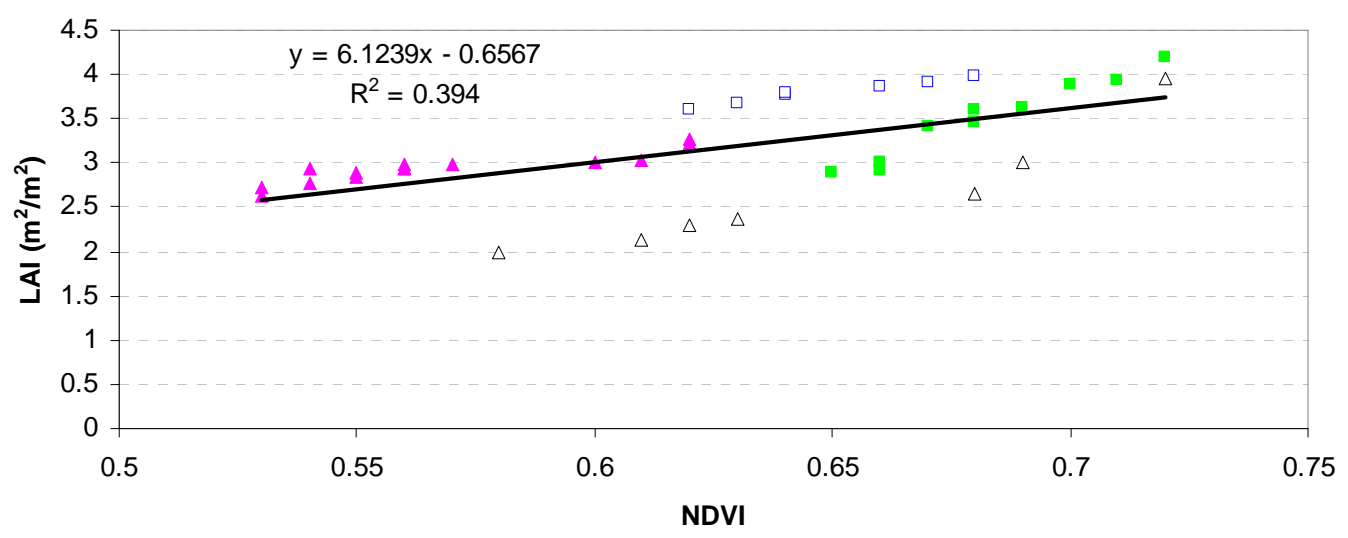

- Wattle 4yr $\triangle$ Pine 12yr $\square$ Pine 15yr $\triangle$ Eucalyptus 10yr

Fig. 2. Relationship between observed LAI and NDVI at Mistley-Canema Estate on 21 June 2007.

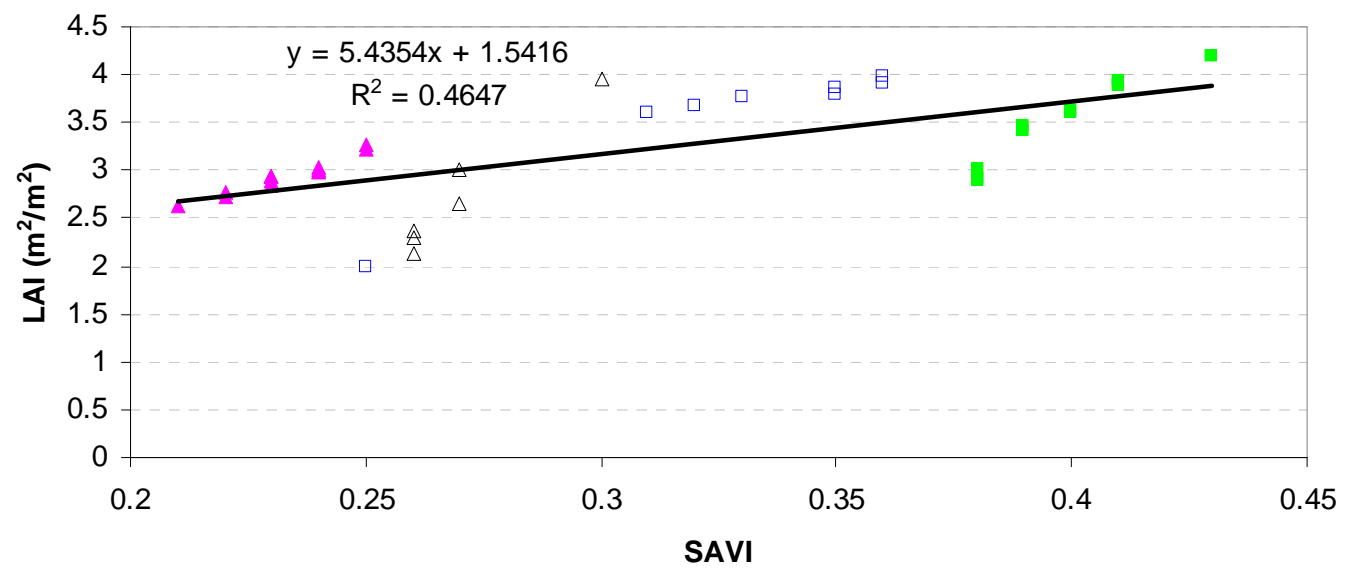

- Wattle 4yr $\triangle$ Pine 12yr $\square$ Pine 15yr $\triangle$ Eucalyptus 10yr

Fig. 3. Relationship between observed LAI and SAVI at Mistley-Canema Estate on 21 June 2007.

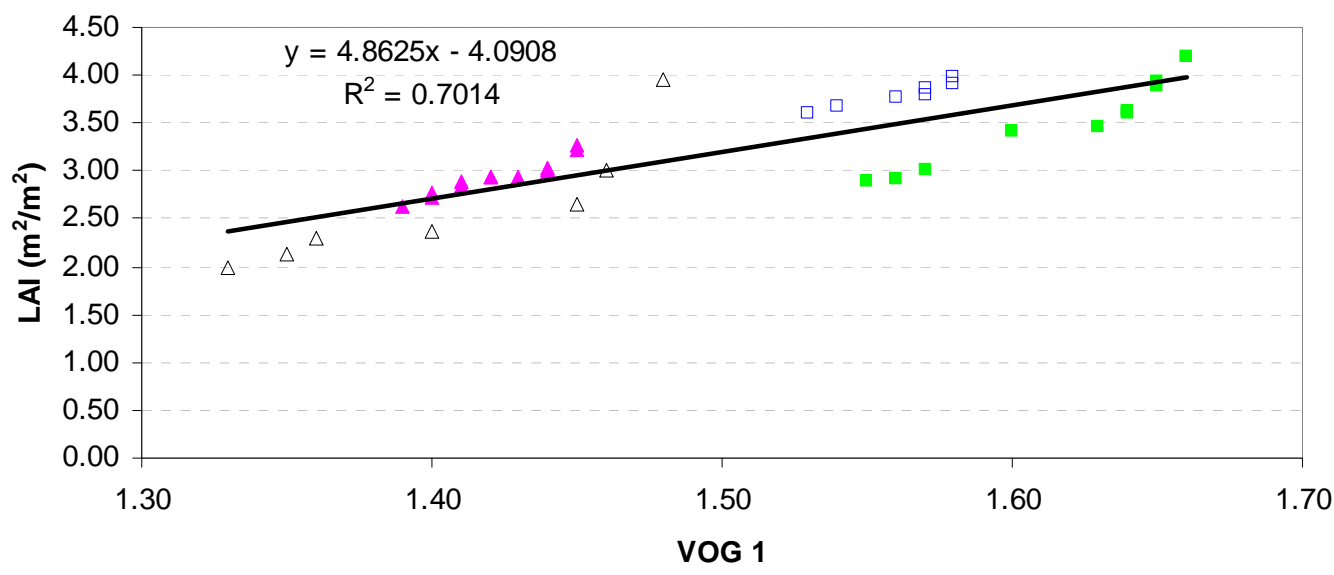

— Wattle 4yr ^ Pine 12yr $\square$ Pine 15yr $\triangle$ Eucalyptus 10yr

Fig. 4. Relationship between observed LAI and the Vogelmann Index 1 at Mistley-Canema Estate on 21 June 2007. 


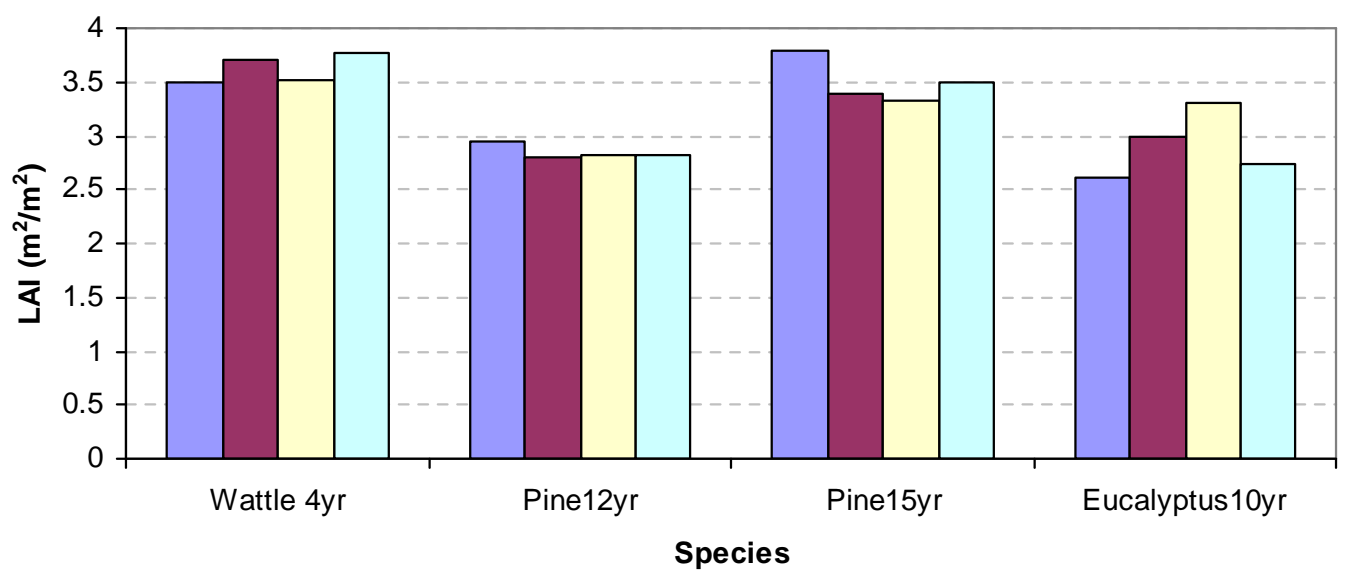

$\square$ observed $\square$ SAVI $\square$ NDVI $\square$ VOG 1

Fig. 5. Average LAI estimated using three different vegetation indices.

Table 1. LAI measurements taken with the LI-COR LAI 2000 canopy analyzer in four commercial forest stands at MistleyCanema on 21 June 2007 at 04:30 p.m. on a clear and sunny day, used for model validation.

\begin{tabular}{cccc}
\hline $\begin{array}{c}\text { Pine } \\
\text { 12 year }\end{array}$ & $\begin{array}{c}\text { Pine } \\
\text { 15 year }\end{array}$ & $\begin{array}{c}\text { Wattle } \\
\text { 4 year }\end{array}$ & $\begin{array}{c}\text { Eucalyptus } \\
\text { 10 year }\end{array}$ \\
\hline 2.62 & 3.61 & 2.89 & 1.98 \\
2.72 & 3.67 & 2.92 & 2.13 \\
2.84 & 3.76 & 3.00 & 2.29 \\
2.89 & 3.80 & 3.41 & 2.36 \\
2.93 & 3.85 & 3.46 & 2.65 \\
2.94 & 3.90 & 3.60 & 3.01 \\
2.99 & 3.99 & 3.62 & 3.95 \\
3.02 & 3.79 & 3.89 & 2.62 \\
3.22 & 3.81 & 3.94 & 2.71 \\
3.26 & 3.76 & 4.19 & 2.53 \\
\hline
\end{tabular}

Figure 4 shows that the LAI of all species can be estimated with a fair degree of accuracy using the Vogelmann index 1. Pine 12 shows the best correlation with the regression model.

Based on the analyses above, of the three vegetation indices used in this study, the Vogelmann index 1, was the most successful for estimating the LAI for all species. The $R^{2}$ and the RMSE values as shown in Table 2, for each of the three vegetation indices used, confirm that the Vogelmann index 1 is the most suitable index to use for the estimation of LAI in this case study. The Vogelmann index 1 performed better than the NDVI and SAVI because it is a narrowband index as apposed to a broadband index. The NDVI and SAVI are susceptible to saturating in dense vegetation. This saturation occurs when the vegetation index no longer increases significantly with an increase in biomass or LAI as can be seen when using the SAVI for wattle $4 \mathrm{yr}$ and eucalyptus $10 \mathrm{yr}$
Table 2. Accuracy assessment results.

\begin{tabular}{ccc}
\hline Vegetation Index & $R^{2}$ & RMSE \\
\hline NDVI & 0.39 & 0.43 \\
SAVI & 0.46 & 0.41 \\
VOG 1 & 0.70 & 0.30 \\
\hline
\end{tabular}

where the slope of the of the data points increases steeper than the trendline. The narrowband VOG 1 index penetrates deeper through the canopy and allows for better estimations of biomass or LAI in denser vegetation. A comparison of the estimated and observed LAI values for each land use is shown in Fig. 5.

Figure 5 shows that the average estimated LAI values correspond well with the observed values.

Using this information, the data obtained from the Hyperion image can be converted into an image of LAI for the study area as shown in Fig. 6, which has been performed using the Vogelmann index 1. Furthermore, the image that has been created for the LAI (Fig. 6) can be used to estimate the maximum storage capacity as shown in Fig. 7, by applying the von Hoyningen-Huene (1981) equation (Eq. 1). Similarly, the daily interception could be estimated if the daily rainfall was known by using Eq. (4), described in Sect. 2.

Figure 7 represents the maximum storage capacity for the same classes (i.e. using the same LAI values) as represented in Fig. 6.

\section{Discussion and conclusion}

Field based methods of estimating LAI and biomass of forestry plantations are expensive and time consuming. Remotely sensed LAI values provide a means of gaining spatial 


\section{LAl determined using Vogelman Index 1}

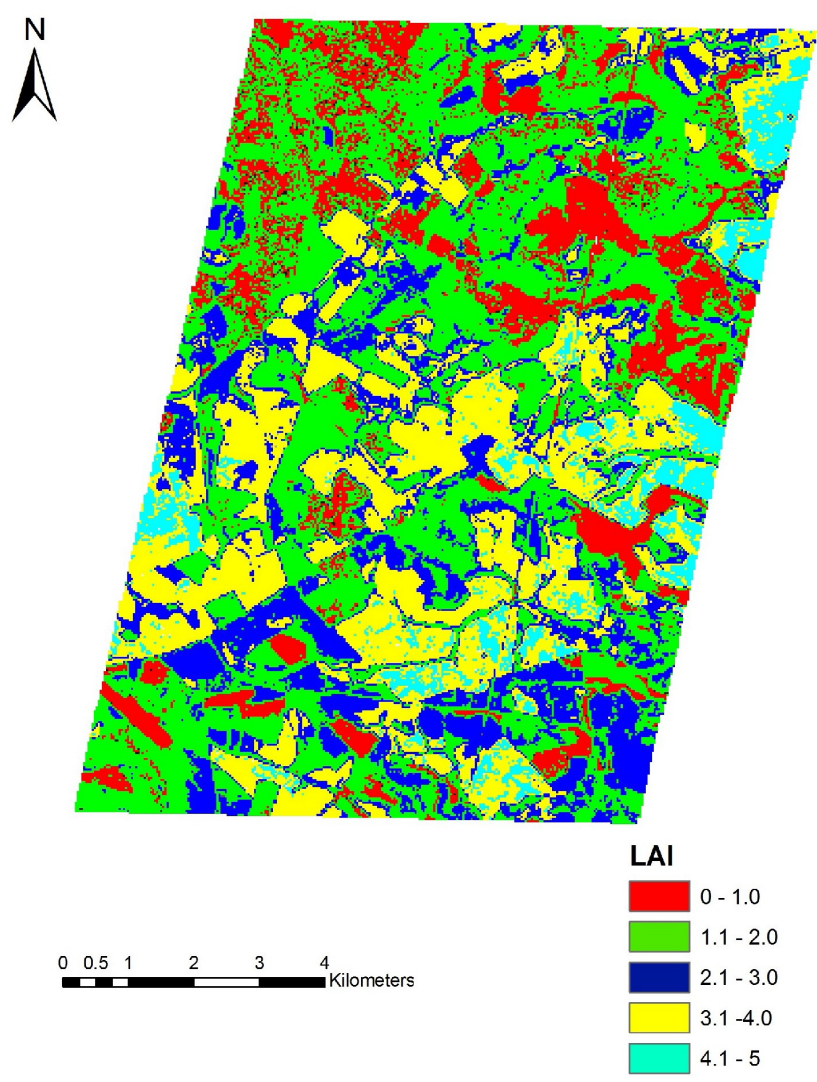

Fig. 6. The LAI distribution over the Mistley-Canema Estate using the Vogelmann index 1 on 21 June 2007.

information about various plant biophysical attributes that can be used in hydrological and process based growth models and can be determined relatively cheaply and easily using satellite imagery (Megown et al., 2000). The ability to remotely predict LAI and eventually water use over a large area is sought after by various stakeholders and the forestry industry, as well as water resources managers and planners. Due to the future availability and accessibility of hyperspectral sensors in southern Africa there should be an increased interest in using high spectral resolution data for a wide variety of environmental applications

There has however been a reluctance to use remote sensing for hydrological applications by the hydrology community at large and in southern Africa in particular. This can be attributed to reasons such as, the unavailability to the relevant hardware and software, lack of knowledge of the application of remote sensing techniques and the reluctance to change conventional and well established methods (Shultz and Engman, 2002). Now in its 4th decade, the use of earth

\section{Maximum Storage Capacity determined using Vogelman Index 1}

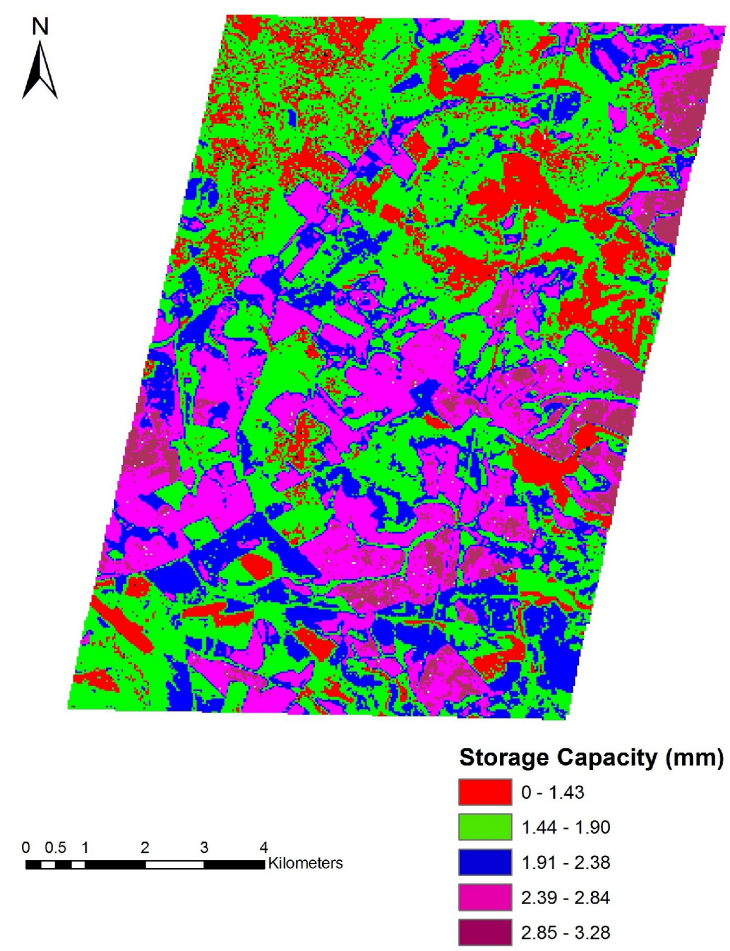

Fig. 7. The maximum storage capacity over the Mistley-Canema Estate using the Vogelmann index 1 on 21 June 2007.

observation data in water resources is however becoming increasingly popular and has been used by researchers such as Dye et al. (2002), Ghebremicael et al. (2004), Sprintsin et al. (2007), Kongo and Jewitt (2007), to mention but a few.

The results obtained from this study show that the use of remote sensing for the estimation of LAI is possible with a relatively high degree of accuracy. The potential to use remote sensing to estimate LAI on a large scale and link this to water resources studies at various scales is just one possible application. For example, with this data, the canopy interception can be estimated using the equations described in Sect. 2 and represented visually to obtain a better understanding of the spatial variability of canopy interception or maximum storage capacity, as shown in Fig. 7. The methodology used in this study is repeatable elsewhere, but the models developed are site and image specific and should not be used elsewhere. This is because the reflectance values would vary in different images depending on which satellite was used to acquire the image and how the image was corrected.

It can be concluded from this study that remote sensing is a valuable tool for the estimation of LAI for applications in hydrology, such as modelling canopy interception. With a limited amounted of field work, LAI measurements can 
be utilised at large spatial scales, and with the launch of southern African satellites, data availability should improve. Although remote sensing may reduce the amount of field work needed, it cannot be excluded completely without a detrimental impact and high levels of uncertainty on the outcome of the task. It is important to accurately estimate LAI as Xiao et al. (1998) found that modelling canopy interception was most sensitive to storage capacity and LAI as the storage capacity is directly related to the LAI. Similarly, Limousin et al. (2008) found that a $25 \%$ reduction in storage capacity reduces interception loss by $8.6 \%$

The most robust vegetation index in this study was found to be the Vogelmann index 1 having an $R^{2}$ value of 0.7 and RMSE of 0.3. The Vogelmann index 1 was developed to be used with high spectral resolution data such as the hyperspectral data used in this study and justifies the good results obtained. Also, the Vogelmann index 1 performed better than the NDVI and SAVI because it is a narrowband index as apposed to a broadband index. NDVI and SAVI are susceptible to saturating in dense vegetation. This saturation occurs when the vegetation index no longer increases significantly with an increase in biomass or LAI. This can be seen when using the SAVI for wattle $4 \mathrm{yr}$ and eucalyptus $10 \mathrm{yr}$ where the slope of the of the data points increases steeper than the trendline. The narrowband VOG 1 index penetrates deeper through the canopy and allows for better estimations of biomass or LAI in denser vegetation. The SAVI and NDVI had $R^{2}$ values of 0.46 and 0.39 , and RMSE of 0.43 and 0.41 respectively. However, the SAVI and NDVI were able to be used to estimate certain species accurately. For example, NDVI can be used to estimate the LAI of 12 year old Pinus patula and 4 year old wattle accurately, even though it is not as robust for all species as the Vogelmann index 1. Although the SAVI and NDVI might not have produced results that are as good as the Vogelmann index 1, it can be seen from Fig. 5 that the difference between the observed and predicted values using the SAVI and NDVI are acceptable and suitable to use in the estimation of canopy interception. Although the results obtained in this study indicate that remote sensing techniques can be used in interception studies, further fieldwork to verify the model is needed. Such field work on interception at compartment scale as well as national scale are ongoing, and form a second complementary phase to this study.

Acknowledgements. The authors would like to thank the CSIR for the loan of equipment. Furthermore, thanks are extended to the Water Research Commission for the funding and imagery for this project, and to Mondi for access to the study site.

Edited by: N. Verhoest

\section{References}

Baret, F. and Guyot, G.: Potentials and limits of Vegetation Indices for LAI and APAR assessment, Remote Sens. Environ., 35, 161173, 1991.

Beven, K. J.: Rainfall-Runoff modelling: the primer, John Wiley \& Sons, Chichester, UK, 2001.

Bongonko, M. N.: Hyperspectral Remote Sensing of Soil Moisture Gradients in Millingerwaard, The Netherlands, http://phylares.vub.ac.be/Thesissen/2005\%20Michael\%

20Ndemo\%20Bogonko.pdf, last access: 24 February 2009, 2005.

Burger, C., Everson, C. S., and Savage, M. J.: Comparative evaporation measurements above commercial forestry and sugarcane canopies in the KwaZulu-Natal Midlands, Ninth South African National Hydrology Symposium, 1-9, 1999.

Camp, K. G. T.: The Bioresources Groups of KwaZulu-Natal, Cedara Report N/A/97/6, KwaZulu-Natal Department of Agriculture, Pietermaritzburg, 1997.

David, J., Valente, F., and Gash, J. H. C.: Evaporation of intercepted rainfall. In: ed. Anderson, M.G. Encyclopedia of Hydrological Science, John Wiley \& Sons Ltd, West Sussex, England, chapter 43, 627-634, 2005.

Delegido, J., Fernandez, G., Gandia, S., and Moreno, J.: Retrieval of chlorophyll content and the LAI of crops using hyperspectral techniques: applications of PROBA/CHRIS data, Int. J. Remote Sens., 29(24), 7107-7127, 2008.

Dye, P., Megown, R., Jacobs, S., Drew, D., Megown, K., Dicks, M., Mthembu, S., and Pretorius, C.: Determining the water use and growth of forest plantations through the GIS-based integration of remote sensing and field data in the 3-PG model, Water Research Commission, Report No. 1194/1/02. Pretoria, 2002.

Everson, C., Moodley, M., Gush, M., Jarmain, C., Govender, M. and Dye, P.: Can effective management of riparian zone vegetation significantly reduce the cost of catchment management and enable greater productivity of land resources, Water Research Commission, Pretoria, Report K5/1284, 2006.

Gash, J. H. C., Lloyd, C. R., and Lachaud, G.: Estimating sparse forest rainfall interception with an analytical model, J. Hydrol., 170, 79-86, 1995.

Gates, D. M.: Biophysical Ecology, Springer-Verlag, New York, 611 pp., 1980

GCIS: South African Yearbook 2006/7: Water affairs and forestry, http://www.gcis.gov.za/resource_centre/sa_info/yearbook/2007/ chapter23.pdf, last access: 14 April 2009, 2007.

Ghebremicael, S. T., Smith, C. W., and Ahmed, F. B.: Estimating the leaf area index (LAI) of black wattle from Landsat ETM+ satellite imagery, Southern African For. J., 201, 3-12, 2004.

Godsmark, R.: The South African forestry and forest production industry 2007, http://www.forestry.co.za/, last access: 17 March 2009, 2008.

Govender, M., Chetty, K. T., and Bulcock, H. H.: A review of hyperspectral remote sensing and its application in vegetation and water resources studies, Water SA, 33, 145-151, 2007.

Gush, M. B.: Estimation of Streamflow Reduction Resulting from Commercial Afforestation in South Africa, Unpublished Manuscript, University of Natal. Pietermaritzburg, 2000. 
Haboudane, D., Miller, J. R., Pattey, E., Zarco-Tejada, P. J., and Strachan, I. B.: Hyperspectral vegetation indices and novel algorithms for predicting green LAI of crop canopies: Modeling and validation in the context of precision agriculture, Remote Sens. Environ., 90, 337-352, 2004.

Hörmann, G.: SIMPEL: A family of simple soil water models, http://www.hydrology.uni-kiel.de/ $\sim$ schorsch/simpel/ englisch/simpel_english.pdf, 2003.

Jewitt, G. P. W.: 8\%-4\% debate: Commercial afforestation and water use in South Africa, Southern African J. For., 194, 4-6, 2002.

Jewitt, G.P.W.: Water and forests, in: Encyclopedia of Hydrological Science, edited by: Anderson, M. G., John Wiley \& Sons Ltd., West Sussex, England, chapter 186, 1-15, 2005.

Kongo, V. M. and Jewitt, G. P. W.: Evaporative water use of different landuses in the Thukela river basin assessed from satellite imagery, 13th SANCIAHS Symposium, Cape Town, 2007.

Kozak, J. A., Ahuja, L. R., Green, T. R., and Ma, L.: Modelling crop canopy and residue rainfall interception effects on soil hydrological components for semi-arid agriculture, Hydrol. Process., 21, 229-241, 2007.

LI-COR.: LAI-2000 Plant canopy analyser: Instruction Manual Ed.I, LI-COR Lincoln, Nebraska, USA, 1992.

Landsberg, J. J. and Waring, R. H.: A generalised model of forest productivity using simplified concepts of radiation use efficiency, carbon balance and partitioning, For. Ecol. and Manag., 95, 209228, 1997.

Langrebe, D.: Some fundamentals and methods for hyperspectral image data analysis, P. Soc. Photo-Opt. INS., 3603, 104-113, 1999.

Lillesand, T. M. and Kiefer, R. W.: Remote Sensing and Image Interpretation, John Wiley \& Sons Inc., New Jersey, 1999.

Limousin, J.-M., Rambal, S., Ourcival, J.-M., and Joffre, R.: Modelling rainfall interception in a Mediterranean Quercus ilex ecosystem: Lessons from a throughfall exclusion experiment. J. Hydrol., 357, 57-66. 2008.

McGwire, K., Minor, T., and Fenstermaker, L.: Hyperspectral mixture modeling for quantifying sparse vegetation cover in arid environments, Remote Sens. Environ., 72, 360-374, 2000.

Nemani, R., Keeling, C., Hashimoto, H., Jolly, W., Piper, S., Tucker, C., Myneni, R., and Running, S.: Climate-Driven Increases in Global Terrestrial Net Primary Production from 1982 to 1999 , Science, 300, 1560-1563, 2003.

Okin, G. S., Roberts, D. A., Murray, B, and Okin, W. J.: Practical limits on hyperspectral vegetation discrimination in arid and semiarid environments, Remote Sens. Environ., 77, 212-225, 2001.
Research Systems Inc.: ENVI 4.3: Narrowband Greeness, Boulder, Colorado, 2005.

Savenije, H. H. G.: The importance of interception and why we should delete the term evapotranspiration from our vocabulary, Hydrol. Process., 18, 1507-1511, 2004.

Schultz, G. A. and Engman, E. T.: Remote Sensing in Hydrology and Water Management, Springer, Heidelberg, Germany, 2000.

Schulze, R. E.: Hydrology and Agrohydrology: A Text to Accompany the ACRU 3.00 Agrohydrological Modelling System. Water Research Commission, Pretoria, RSA, WRC Report No. TT69/95, 1995.

Sprintsin, M., Karnieli, A., Berliner, P., Rotenberg, E., Yakir, D., and Cohen, S.: The effect of spatial resolution on the accuracy of leaf area index estimation for a forest planted in the desert transition zone, Remote Sens. Environ., 109, 416-428, 2007.

Van Dijk, A. I. J. M. and Bruijnzeel, L. A.: Modelling rainfall interception by vegetation of variable density using an updated analytical model. Part 1. Model description, J. Hydrol., 247, 230238, 2001a.

Van Dijk, A. I. J. M. and Bruijnzeel, L. A.: Modelling rainfall interception by vegetation of variable density using an updated analytical model. Part 2. Model validation for a tropical upland mixed cropping system, J. Hydrol., 247, 239-262, 2001 b.

Vogelmann, J. E., Rock, B. N., and Moss, D. M.: Red Edge Spectral Measurements from Sugar Maple Leaves. Int. J. Remote Sens., 14, 1563-1575, 1993.

Von Hoyningen-Huene, J.: Die interzeption des Niederschlages in landwirtschaftlichen Pflanzenbeständen. Arbeitsbericht Deutscher verband fur Wasserwirtschaft und Kulturbau, DVWK, Braunschwig, Germany, 1981.

Von Hoyningen-Huene, J.: Die interzeption des Niederschlages in landwirtschaftlichen Pflanzenbeständen, Deutscher Verband fur Wasserwirtschaft und Kulturbau, Verlag Paul Parey-Hamburg, Schirften, 57, 1-66, 1983.

Xiao, Q., McPherson, E. G., Ustin, S. L., and Grismer, M. E.: A new approach to model tree rainfall interception, AGU Fall meeting, San Francisco, CA, 1998.

Zhang, B., Song, K., Zhang, Y., and Wang, Z.: Study on the relationship between hyperspectral reflectance and soybean LAI, above ground biomass, Int. Geosci. Remote Se., 5, 3583-3586, 2005. 